\title{
A cobertura jornalística das audiências públicas nas mídias legislativas ${ }^{1}$
}

\author{
Cristiane Brum Bernardes* \\ Antonio Teixeira de Barros**
}

Artigo recebido em:

6 de julho de 2010

Aprovado em:

29 de setembro de 2010

* Jornalista,

Analista Legislativa da Câmara dos

Deputados, Mestra em Comunicação e Informação (UFRGS) e doutoranda em Ciência Política (IUPERJ).

cris.brum@gmail.com

** Doutor em Sociologia e mestre em Comunicação.

Docente e pesquisador do

Programa de Pós-

Graduação do Centro de Formação,

Treinamento e

Aperfeiçoamento da Câmara dos Deputados. Coordenador do grupo de pesquisa

"Comunicação Pública no Legislativo: aspectos teóricos/ conceituais, diretrizes editoriais e práticas profissionais", filiado à linha de pesquisa

"Cidadania, práticas democráticas de representação, participação política, comunicação e educação".

antonibarros@gmail.com

Resumo: Analisa o papel das audiências públicas realizadas na Câmara dos Deputados como instrumentos de participação política e de cidadania. A partir de um breve resumo teórico sobre a criação e estruturação da audiência pública no Brasil, descreve-se a cobertura jornalística das audiências feita pelos veículos de comunicação legislativos, apontando as limitações e os problemas da atividade. A conclusão é que apesar das potencialidades do instrumento, ainda são necessários ajustes para que as audiências públicas realmente sejam apropriadas pela população brasileira como instrumento de participação na elaboração das políticas públicas.

Palavras-chave: Audiências públicas; participação política; mídias legislativas.

\section{The news coverage of public hearings on legislative medias}

Abstract: Examines the role of public hearings held in the Chamber of Deputies as instruments of political participation and citizenship. From a brief theoretical summary on the creation and structuring of the public hearing in Brazil, describes the coverage of the public hearings made by legislative media, pointing out the limitations and problems of activity. The conclusion is that despite the potential of the instrument, adjustments are still required to ensure that the public hearings are appropriate for the Brazilian population as an instrument of participation in the elaboration of public policies.

Keywords: Public hearings; political participation; legislative media.
Este artigo é resultado das atividades institucionais inseridas no projeto integrado de pesquisa "Comunicação Pública no Legislativo: aspectos teóricos/conceituais, diretrizes editoriais e práticas profissionais". O grupo é filiado à linha de pesquisa "Cidadania, práticas democráticas de representação, participação política, comunicação e educação" do Programa de Pós-Graduação do Centro de Formação, Treinamento e Aperfeiçoamento (CEFOR) da Câmara dos Deputados. 


\section{Introdução}

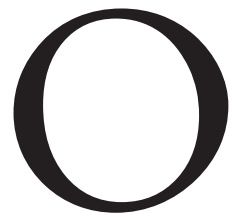

riunda do direito anglo-saxão, a audiência pública é um dos mecanismos para assegurar a participação da sociedade civil nos debates políticos e administrativos. No Brasil, é resultado das motivações democratizantes que inspiraram a Constituição de 1988. O Regimento Interno da Assembleia Constituinte previa formas de apresentação de sugestões de entidades representativas da sociedade por meio de plebiscito, referendo e apresentação de emendas populares. Entretanto, essas formas que fortaleceram o caráter democratizante da nova Carta eram extremamente complexas de efetivar e, por isso, alcançaram pouco resultado (GUERRA, 2010). As audiências públicas, portanto, tornaram-se o instrumento mais recorrente para a participação popular na elaboração das políticas públicas, tanto na esfera do Poder Legislativo, como nos demais poderes.

Inserido no rol dos direitos de participação política, o instituto das audiências públicas baseia-se no pressuposto de que o cidadão não deve ser mero observador da cena pública ou agente passivo do processo político ou administrativo. Assim, trata-se de um expediente considerado indispensável para o fortalecimento das práticas de democracia e de cidadania no contexto atual. Diferentemente da sessão pública, na qual o público apenas assiste ao debate, na audiência pública os representantes da coletividade podem se manifestar de forma ativa, asssegurando aos cidadãos o direito de colaborar e de ser ouvido. Dessa forma, esse instrumento permite o fortalecimento dos vínculos entre a sociedade e o Estado, além de possibilitar a renovação do diálogo entre os agentes públicos e a população. É também considerado "mecanismo idôneo de formação de consenso da opinião pública", além de "elemento de democratização do poder e modo de participação no poder público” (DAL BOSCO, 2002, p. 155).

Nessa mesma linha de pensamento, Habermas (1987a; 1987b) destaca a importância do diálogo entre as instituições do Estado e da sociedade civil, além dos próprios cidadãos. É oportuno situar a discussão habermasiana em sua Teoria da Ação Comunicativa, cujo núcleo são os conceitos de agir estratégico e agir comunicativo. Sob essa perspectiva teórica, em termos gerais, o primeiro conceito faz parte da noção de mundo sistêmico ${ }^{2}$, entendido como a esfera da sociedade que compreende o universo das relações normativas e regulamentadas, resultantes do modelo de sociedade contratual. O segundo conceito está vinculado ao mundo vivido ${ }^{3}$ como a esfera que contribui para

\footnotetext{
${ }^{2}$ De forma mais detalhada, o mundo sistêmico pode ser entendido como a esfera da ação instrumental, planejada, estratégica, regida por uma racionalidade determinada, o que implica um modelo de comunicação igualmente estratégica e instrumental, ou seja, voltada para fins e objetivos específicos e pré-determinados. Toda a ação e comunicação no âmbito do mundo sistêmico são pautadas por mecanismos burocráticos que limitam e controlam as decisões voluntárias, as manifestações espontâneas dos indivíduos e da livre expressão do pensamento e da opinião.

${ }^{3} \mathrm{O}$ mundo da vida compreende três elementos estruturais: a cultura, a sociedade e a personalidade. O primeiro é entendido por Habermas como o acervo de saberes acumulado historicamente, em que os participantes da comunicação se abastecem de interpretações para entender algo do mundo. $O$ segundo é concebido como um sistema composto por ordenações legítimas, mediante as quais os participantes dos processos interativos regulam sua forma de participação e pertencimento a grupos sociais e instituições. Já o terceiro, caracterizado pela personalidade, é traduzido pela competência nos processos que possibilitam a um sujeito ter linguagem e ação, que o habilitam a fazer parte de processos de entendimento e compartilhamento de signos, além de afirmar neles sua própria identidade.
} 
manter a identidade social e cultural dos indivíduos e comunidades, ao favorecer o compartilhamento de valores, a livre expressão de idéias, a comunicação de natureza mais participativa e menos instrumental.

As audiências públicas devem ser analisadas tanto do ponto de vista estratégico (mundo sistêmico), como sob a ótica comunicativa (mundo vivido). Em relação ao primeiro, trata-se de um instrumento da burocracia, voltado para atingir determinados objetivos, sujeito a normas e protocolos, os quais tanto podem favorecer como atrapalhar a participação social, a depender das estratégias adotadas e do uso final dos resultados obtidos. Mas as audiências também podem ser consideradas formas de diálogo com os atores e sujeitos sociais, elementos para fortalecer a coesão do tecido social e estimular as práticas de cidadania e democracia, numa perspectiva alinhada à ação comunicativa. Isso depende, contudo, de como tais audiências são realizadas e sobretudo como são aproveitadas pelas instituições que as promovem. O ideal seria a conciliação entre os aspectos estratégicos e comunicativos, além de uma articulação sistemática com os demais mecanismos de participação social disponibilizados pela instituição, a fim de aumentar o índice de responsividade social e accountability (MARQUES, 2010).

\section{O instituto das}

audiências públicas baseia-se no

pressuposto de que

o cidadão não deve ser mero observador da cena pública

Após essa breve abordagem teórica ${ }^{4}$, apresentam-se algumas formas de aproveitamento das audiências públicas pela Câmara dos Deputados. O foco das considerações não é o funcionamento das audiências em si, mas a cobertura jornalística que delas fazem as mídias legislativas: TV Câmara, Rádio Câmara, Agência Câmara e Jornal da Câmara. O objetivo, portanto, é verificar de que forma a Câmara dos Deputados torna visível essa forma de participação popular para o cidadão que não tem acesso direto à instituição.

Em termos metodológicos, o estudo é fruto da coleta de dados por meio de entrevistas e do acompanhamento direto das audiências públicas durante cinco anos (2005 a 2010), uma espécie de observação participante, uma vez que os autores atuaram na cobertura relizada pelos diferentes veículos no referido período. A análise resulta, portanto, da prática cotidiana, além da participação direta nas reuniões internas, seminários institucionais, cursos, treinamentos profissionais e conversas informais com os demais integrantes da equipe responsável pela cobertura das audiências na Câmara dos Deputados.

\section{Audiências públicas no Poder Legislativo}

O Poder Legislativo tem nas audiências públicas espaços democráticos de debates entre parlamentares e a sociedade que subsidiam os parlamentares para o exercício de suas funções institucionais (GUERRA, 2010). A realização dessas audiências decorre de comando constitucional (art. 58, parágrafo

\footnotetext{
${ }^{4}$ Em termos teóricos, o artigo constitui desdobramento de outro estudo por nós realizado (BARROS, A. T; BERNARDES, C. B. ; LEMOS, C. R. F. As mídias legislativas e a redefinição da noticiabilidade política no Brasil. Em Questão (UFRGS. Impresso), v. 14, p. 17-23, 2008), além de se inserir na perspectiva analítica de ALDÉ, 2004; MATOS, 1999; e RENAULT, 2004.
} 
$2^{\circ}$, inciso II, da CF de 1988), cabendo às duas Casas do Congresso Nacional sua implementação. Segundo Celso Ribeiro Bastos (1995) "as audiências públicas com entidades da sociedade civil são realizadas quando questões de interesse social ou mesmo de segmentos específicos da sociedade forem suscitadas, tais audiências, portanto, configuram espaços voltados ao debate coletivo".

A Câmara dos Deputados, como espaço legítimo da representação social por meio dos deputados federais, incorporou às rotinas de trabalho o debate com entes da sociedade civil. Esses debates são previstos pelo Regimento Interno da Câmara dos Deputados (RICD, artigos 255-258). O primeiro deles define as linhas gerais que as comissões devem seguir para a execução dos debates:

Art. 255. Cada Comissão poderá realizar reunião de audiência pública com entidade da sociedade civil para instruir matéria legislativa em tramite, bem como para tratar de assuntos de interesse público relevante, atinentes à sua área de atuação, mediante proposta de qualquer membro ou a pedido de entidade interessada.

Na sequência, o RICD define a dinâmica da seleção dos convidados:

Art. 256. Aprovada a reunião de audiência pública, a Comissão selecionará, para serem ouvidas, as autoridades, as pessoas interessadas e os especialistas ligados às entidades participantes, cabendo ao Presidente da Comissão expedir os convites.

Parágrafo $1^{\circ}$. Na hipótese de haver defensores e opositores relativamente à matéria objeto de exame, a Comissão procederá de forma que possibilite a audiência das diversas correntes de opinião.

Parágrafo $2^{\circ}$. O convidado deverá limitar-se ao tema ou questão em debate e disporá, para tanto, de vinte minutos, prorrogáveis a juízo da Comissão, não podendo ser aparteado.

Parágrafo único. Será admitido, a qualquer tempo, o traslado de peças ou fornecimento de cópias aos interessados”.

Percebe-se que as principais características das audiências públicas defendidas pelo RICD são a transparência e o debate efetivo sobre matéria relevante e de interesse coletivo. Contudo, a prática é passível de várias críticas, tanto pelo formato como pela condução e uso técnico/político das discussões. Entre essas críticas podemos destacar, em nível mais geral, o poder discricionário dos líderes das comissões e dos deputados integrantes dos colegiados de livre escolha dos convidados, o que pode limitar o enfoque e o enquadramento das discussões, além de enviesar o teor das análises em pontos que interessam ao parlamentar. 
Outra ressalva diz respeito ao modelo de debate adotado, com muito tempo destinado à apresentação das diferentes posições e pouco tempo para um efetivo debate entre os participantes, algo que reproduz a polarização que reina nas discussões no Parlamento, a exemplo das votações em Plenário, com posições contrárias ou favoráveis decididas de antemão, e não durante a discussão propriamente dita. Um debate polêmico, no sentido estrito do termo, não poderia se restringir a duas visões pré-concebidas, o que limita a abordagem e leva o cidadão a pensar que só resta aderir a uma delas.

A cada ano, as 20 comissões permanentes e as várias comissões especiais da Câmara realizam quase duas mil audiências públicas 5 . A maioria absoluta delas ocorre de terça a quinta-feira, período em que os parlamentares concentram sua atividade em Brasília. Num cálculo simples ${ }^{6}$, percebe-se que a média de eventos de terça a quinta é de quase 15 por dia. Em raras ocasiões os deputados realizam audiências nos estados, geralmente para tratar de temas de interesse das comissões especiais. Por esse motivo, muitos eventos acabam acontecendo ao mesmo tempo, nos plenários das comissões ${ }^{7}$, o que inviabiliza a cobertura completa deles pelos veículos de comunicação da Casa.

Uma das soluções encontradas para dar visibilidade às audiências e reuniões que acabavam de fora da cobertura das mídias legislativas foi a criação, em outubro de 2009, do WebCâmara, serviço de transmissão pela internet da imagem e do áudio dos eventos que acontecem nos plenários das comissões. Dessa forma, o internauta interessado no assunto de uma audiência pode acompanhá-la em tempo real, mesmo que a transmissão não esteja sendo feita pela TV ou pela Rádio Câmara.

Como mencionado anteriormente, a Câmara tem quatro veículos de mídia: tevê, rádio, jornal e agência de notícias. A cobertura jornalística das atividades parlamentares e a transmissão ao vivo das sessões e debates são os principais objetivos deles. A TV Câmara foi inaugurada em 1998 e funciona 24 horas por dia, sete dias por semana. Pela definição da Lei de Cabo (Lei 8977/1995), sua função prioritária é transmitir, ao vivo, as sessões do Plenário da instituição. O canal transmite, também ao vivo ou gravados, trabalhos de outras instâncias da Câmara, como as 20 comissões permanentes e as comissões parlamentares de inquérito (CPIs). A programação inclui ainda telejornais, debates e entrevistas, documentários e outros formatos televisivos.

A Rádio Câmara, por sua vez, foi criada em 1999, a partir do núcleo de profissionais encarregados de produzir o noticiário da Câmara no programa A Voz do Brasil, tarefa realizada desde 1963. A emissora comporta ainda a produção de radiojornal, boletins informativos e programas especiais diários/ semanais para discutir assuntos de interesse geral, como ecologia, saúde, educação e economia.

\footnotetext{
${ }^{5}$ Informação confirmada pelo Diretor de Comunicação Institucional da Secretaria de Comunicação Social (SECOM) da Câmara dos Deputados, William França, em entrevista à pesquisadora Cristiane Brum Bernardes. Além das audiências, a Câmara realiza quase 500 eventos por ano, entre seminários, conferências, congressos e exposições.

${ }^{6}$ Excluindo os períodos de recesso, nos meses de janeiro e julho, os 2000 eventos são distribuídos entre 46 semanas, com realização em três dias consecutivos (terça a quinta-feira), totalizando 14,8 eventos por dia.

${ }^{7}$ Os plenários das comissões são 16 salas localizadas no Anexo II da Câmara, destinados às reuniões ordinárias e audiências públicas promovidas pelas comissões.
} 
O Jornal da Câmara é editado desde 1971. Atualmente, com edições diárias de segunda a quinta-feira com 8 páginas e tiragem de 5 mil exemplares. A edição semanal, da sexta-feira, tem 12 mil exemplares e é enviada para prefeituras, câmaras de vereadores e assembleias legislativas do País, bem como órgãos do Judiciário. Faz a cobertura das comissões técnicas e dá ênfase aos discursos e votações realizadas no Plenário.

A Agência Câmara de Notícias foi criada em 2000 para ampliar a visibilidade das atividades legislativas e divulga, em tempo real, o desenrolar das ações institucionais, como votações em plenário, audiências públicas das Comissões Permanentes e Especiais, reuniões de bancadas parlamentares, entre outras atividades. Também divulga todas as propostas e projetos de lei apresentados à Câmara. Além da cobertura jornalística em tempo real, a Agência oferece informações sobre a pauta de votações do dia, o resumo da pauta de votações da semana, notícias consolidadas sobre cada fato noticiado em tempo real, reportagens especiais que abordam as propostas em tramitação sobre grandes temas. Disponibiliza ainda um boletim eletrônico, distribuído gratuitamente, com as principais notícias do dia sobre os trabalhos das comissões e votações no plenário. Também promove bate-papos (chats) entre deputados, especialistas e internautas, com o objetivo de discutir projetos da pauta da Câmara. A seguir, um breve detalhamento da cobertura feita pelas mídias legislativas.

\section{Cobertura jornalística das audiências}

Para articular a cobertura jornalística de quatro veículos diferentes, foi criada em 2003 a Coordenação de Jornalismo. Sua missão, conforme consta no próprio site da instituição, "é integrar o jornalismo da Rádio, da TV, do Jornal e da Agência de Notícias, para evitar duplicidade de ações e otimizar os recursos humanos disponíveis". Cabe ainda à Coordenação harmonizar o discurso jornalístico dos veículos e zelar pela observação dos princípios de Comunicação Pública. A Coordenação também é responsável por serviços como: orientações aos veículos sobre pautas e coberturas; atendimento a parlamentares e a suas respectivas assessorias, a instâncias da Casa e aos veículos de Comunicação; acompanhamento do noticiário via TV e sites; checagem de informações sobre reuniões de comissões e agenda presidencial, entre outras; e contatos com a assessoria de Comunicação da Presidência da Câmara.

O principal momento da rotina semanal do setor é a reunião de agenda da semana, feita nas segundas-feiras, com os chefes de reportagem e editoreschefe dos quatro veículos: Jornal, Agência, TV e Rádio. Nessa reunião é discutido o que cada veículo irá cobrir durante a semana e se informa aos demais quais serão os profissionais responsáveis pela cobertura. $\mathrm{O}$ documento enviado aos diferentes profissionais é a "agenda da semana", com a previsão de tudo o que vai ocorrer no período nas dependências da Câmara. Apesar dessa previsão semanal, muita coisa pode mudar durante a semana, com novos eventos surgindo e muitas pautas sendo canceladas, seja por falta de profissionais para a cobertura, seja por motivos institucionais da própria Câmara - falta de quórum para reuniões é o mais comum. 
Em relação à pauta dos veículos, os profissionais ${ }^{8}$ acreditam que eventuais diferenças dizem muito mais respeito à linguagem específica de cada mídia do que a critérios mais substantivos como interesse público ou importância dos fatos. Para a maioria deles, os princípios de cobertura são os mesmos para todos os veículos, mas diferenças práticas nas rotinas ajudam a definir o que cada um deles vai enfatizar diariamente:

Muitas vezes a escolha é feita de acordo com o assunto e com a afinidade do veículo com aquele assunto. Os orçamentos, por exemplo, são assuntos mais complexos. É mais viável explicar uma matéria orçamentária por um texto escrito do que por um texto falado, pela quantidade de números que tem, pela complexidade do assunto (depoimento à pesquisadora).

Apesar da existência da Coordenação de Jornalismo, cada um dos veículos tem autonomia para definir o que seus repórteres vão cobrir. $\mathrm{Na}$ TV Câmara, por exemplo, a definição das matérias factuais é feita na reunião de segundafeira. Nesse encontro, os profissionais discutem quais comissões serão cobertas por repórter, quais vão ser incluídas apenas no “giro”, quais merecem um VT completo, quais entrarão como nota coberta ou apenas menção, nota falada pelo apresentador. Na verdade, no momento em que vão lendo o que está previsto na agenda, os jornalistas já decidem o que pode render ou não imagens. Essa é a preocupação central. Um fato com escassez de imagens televisivas - geralmente eventos que debatem questões teóricas ou conceituais sobre a legislação ou tipos de leis que tratam de conceitos abstratos - só entrará na cobertura como VT se for muito relevante. A reforma política, por exemplo. Não rende boas imagens, mas é vital para o funcionamento da Casa legislativa e é um tema sobre o qual os deputados têm todo o interesse e, por isso, merece cobertura.

No geral, assuntos que dizem respeito a assuntos mais populares ou legislações com efeitos práticos sobre a vida das pessoas - que tratam de medicamentos, do preço dos produtos e serviços, que mudam regras de conduta em situações comuns, etc. - são enfatizados. Além disso, decisões práticas - "tornou-se lei”, “só falta ser sancionado”, “foi aprovado pela Câmara” - também merecem muito mais atenção do que discussões sobre determinados assuntos, especialmente aquelas que estão nas instâncias iniciais do processo legislativo. Por exemplo, projetos apresentados só se tornam pauta se forem muito polêmicos, importantes ou "diferentes", um critério que está ligado a uma popularização da notícia, muito mais usada na televisão do que no jornalismo escrito. Em outras palavras, o que vai acontecer imediatamente tem relevância sobre o que ainda está sendo pensado e debatido.

$\mathrm{O}$ "giro" é composto pelos eventos do dia que não são acompanhados por um repórter. Nesse caso, um produtor fica com uma equipe no corredor das comissões e passa, literalmente, pelas diferentes reuniões a fim de constatar

${ }^{8}$ Os profissionais foram entrevistados entre novembro de 2008 e dezembro de 2009 pela pesquisadora Cristiane Brum Bernardes. Parte das reflexões apresentadas neste artigo foram elaboradas para a tese de doutoramento em Ciência Política da pesquisadora, ainda em fase de conclusão. 
se algo importante acontece em alguma delas. Na rádio eles também fazem algo parecido, mas são os repórteres que cobrem. Como há dúvida sobre os resultados - e não há como desperdiçar uma equipe de televisão com eventos que podem não render nada do ponto de vista jornalístico -, os editores preferem não escolher previamente e deixar que a equipe "sinta o clima" na hora dos fatos. Essas decisões, tomadas pela equipe do veículo, são comunicadas à Coordenação de Jornalismo e repassadas aos demais veículos.

$\mathrm{Na}$ Rádio Câmara, grande parte das pautas tem como base assuntos que são repercutidos na imprensa comercial, especialmente nos jornais diários como Folha de S.Paulo, O Estado de S.Paulo, O Globo, etc. Mesmo na cobertura dos eventos programados na agenda da Câmara, geralmente o material usado como subsídio traz aquilo que já foi publicado pela mídia convencional sobre o assunto. Além disso, ao contrário da Agência e do Jornal, muitas matérias trazem a repercussão, perante os parlamentares, de assuntos que estão na agenda da mídia comercial, algumas vezes relacionando os temas com os projetos que estão na Câmara e audiências feitas na Casa, outras apenas convocando os líderes para opinarem sobre as questões. Por concentrarem grande atenção à Presidência e ao Salão Verde, a Rádio apresenta cobertura bastante parecida com a dos veículos comerciais, ou seja, com menor ênfase às audiências públicas e mais espaço para a repercussão de assuntos entre líderes e parlamentares. Divulgam as mesmas sonoras, focalizam os mesmos assuntos, ouvem as mesmas fontes da mídia comercial.

De certo modo, o Jornal e a Agência são mais independentes da influência externa e mais preocupados com o que ocorre na Câmara. No jornal os assuntos externos só têm espaço quando repercutem no Plenário, isto é, quando os próprios deputados trazem os temas para a tribuna legislativa. Caso contrário, os temas abordados pelo restante da mídia são ignorados. $\mathrm{Na}$ tevê, por outro lado, fatos e decisões relativos ao processo legislativo

A linguagem das mídias legislativas é árida e bastante complexa para alguém com pouca escolaridade compreender são mais relevantes do que a simples opinião dos deputados sobre temas variados, que recebem destaque no Jornal e na Rádio.

A Agência Câmara enfatiza a cobertura das ações legislativas, especialmente audiências e seminários que não recebem atenção dos outros veículos. Temas áridos, debates conceituais e questões mais teóricas ou que ainda estão em fase inicial de discussão recebem a cobertura desse veículo. Assim, o banco de dados informatizado apresenta matérias sobre reuniões de comissões, as decisões sobre as propostas e as opiniões dos parlamentares sobre elas, permitindo a pesquisa completa sobre o andamento do processo legislativo, desde a apresentação das propostas, com o texto dos projetos originais, até a decisão final da Casa.

O fato das propostas serem noticiadas - e as notícias sobre determinados assuntos serem enviadas pelo boletim diário da Agência Câmara aos representantes de várias entidades e também a pessoas físicas interessadas nos temas - permite a visibilidade dos projetos pela sociedade civil. Ou seja, a notícia sobre a apresentação de determinado projeto serve de alerta sobre sua existência aos grupos interessados ou não em sua aprovação. Serve, em última instância, para mobilização social de grupos ou indivíduos, entidades e categorias pro- 
fissionais, por exemplo. Como ressalta um profissional, "a Agência propicia, dá oportunidade para o cidadão comum participar do processo legislativo via internet".

Ao comentarem as funções da Agência Câmara, dois gestores do veículo ressaltaram o papel relativo à transparência do Poder Legislativo e do processo de produção de leis no País. Segundo eles, o objetivo principal da Agência é "mostrar tudo o que ocorre na Câmara" e "o que está acontecendo com os projetos que estão tramitando aqui”. Nesse sentido, a informação seria um ponto de partida importante não apenas para garantir o controle dos representados sobre o representante, mas também para a participação política do cidadão, na linha do que argumentamos acima. Dessa forma, o processo legislativo se torna "rastreável" pelo cidadão, que pode descobrir ainda a posição e as opiniões do seu representante por meio dos veículos:

Você realmente deixar o cidadão por dentro do que acontece nessa Casa que trabalha com todos os grandes assuntos do País. Quer dizer, projetos importantíssimos passam por aqui $\mathrm{e}$ às vezes a pessoa só sabe disso quando o projeto virou lei. Eu acho muito importante que a pessoa tenha ideia de que o projeto tramita por várias comissões, que existem audiências públicas que são realizadas. A gente tem uma preocupação em divulgar a agenda. Quer dizer, as pessoas podem saber que vai ter uma audiência sobre o projeto tal, sobre o tema tal, se ela tiver possibilidade de vir participar da audiência, ela pode vir, opinar, tentar mobilizar pessoas para procurar o relator do projeto, fazer sugestões, fazer críticas. Então, trazer a população para o processo legislativo é um objetivo também muito importante da Agência (depoimento à pesquisadora).

\section{Limitações e problemas na cobertura das audiências}

O espaço para que todos os parlamentares apareçam é um dos diferenciais da cobertura política dos veículos da Câmara, mas os profissionais apontam outras diferenças na forma como as mídias legislativas mostram a política, em relação à mídia comercial. As seis estratégias de noticiabilidade encontradas pelas mídias legislativas para apresentação dos fatos políticos são: pluralização das fontes de informação, divulgação abrangente, aprofundamento da discussão, vinculação entre noticiário e clima de opinião, fornecimento de informação instantânea, e noticiário consolidado?. Em resumo, tais práticas tentam incluir informações mais detalhadas sobre o processo legislativo e a negociação política que ocorre dentro do Congresso, com a finalidade de ampliar a compreensão dos cidadãos sobre o assunto.

Contudo, os próprios jornalistas do sistema têm várias críticas à forma

9 BARROS, A. T; BERNARDES, C. B. ; LEMOS, C. R. F. As mídias legislativas e a redefinição da noticiabilidade política no Brasil. Em Questão (UFRGS. Impresso), v. 14, p. 11-23, 2008. 
como essa cobertura é feita. Para alguns, o viés da cobertura é muito "quantitativo". "Essa visão dos veículos aqui é muito forte, porque é uma Casa tão pichada aí fora que há uma necessidade de ficar mostrando serviço", comenta um profissional. "Então, o tempo todo a preocupação é mostrar o que foi aprovado, o que se está fazendo", conclui. Para ele, contudo, seria importante também mostrar "o que não foi aprovado, ou porque determinada coisa não foi aprovada".

Para outros, a cobertura não consegue, efetivamente, passar do acúmulo dos dados para uma informação realmente explicativa do processo legislativo.

Aí, talvez, seja o ponto em mais falhamos, de, às vezes, não ter tempo, e não conseguir, e não focar as matérias e o conteúdo no que significa aquilo para o ouvinte. Continuamos nessa cobertura 'a reforma política vai ser votada tanto', 'e o líder disse... ', 'e o outro falou... ', 'e a oposição obstrui...' Quer dizer, isso é mais importante, o jogo político é mais importante do que a consequência daquilo ali para as pessoas. Eu acho que a gente deveria mostrar isso. Aprofundar o debate da Reforma Tributária, de repente ouvir outros setores da sociedade. O que está por trás desse jogo (depoimento à pesquisadora).

Além disso, a linguagem das mídias legislativas é complexa, exatamente porque não é nada popular. Aliás, muito pelo contrário, é uma linguagem árida e bastante complexa para alguém com pouca escolaridade compreender. Mesmo as tentativas de simplificação usadas pela equipe resultam em textos complicados, pelo simples motivo de que tratam de assuntos complexos. Uma dificuldade a mais para repórteres e editores, aliás, é a impossibilidade de usar expressões coloquiais, exatamente porque não se está falando da vida cotidiana dos ouvintes, mas do rito, do ritual, do processo legislativo, de uma instituição que tem regras próprias e uma linguagem peculiar também. Como veículos "oficiais" do Parlamento, as mídias legislativas não usam a linguagem coloquial que outros órgãos de imprensa utilizam, especialmente para descrever as ações legislativas.

Conectada a essa questão, está a impossibilidade do profissional dos veículos da Câmara comentar aquilo que está noticiando. Qualquer expressão que demonstre juízo de valor é excluída ou substituída no texto, mesmo que tenha sido incluída apenas com um valor explicativo para o leitor, ouvinte ou telespectador. Mesmo na TV Câmara, veículo que, por definição, é mais informal que o jornal impresso ou rádio, as expressões coloquiais não são utilizadas na produção diária pela equipe. Sem a possibilidade de comentar o que está vendo, torna-se muito mais difícil para o jornalista sair da linguagem formal do Legislativo e explicar, com uma linguagem simples e coloquial, o que está acontecendo.

Ao jornalista só é permitido relatar o que acontece no espaço público, sem comentar os fatos ou provocar o confronto de idéias, segundo os termos usados por Charaudeau (2007). Isso, como já ressaltamos, dificulta o cumprimento da tarefa de informar em profundidade o público, já que nenhuma aná- 
lise pode acompanhar o relato dos fatos e até mesmo as explicações ficam mais complexas, uma vez que não cabe ao jornalista avaliar o que está relatando.

\section{Considerações finais}

Os sistemas públicos de informação, como o que é mantido pela Câmara dos Deputados, existem, em tese, para atender aos interesses públicos, especialmente no caso da cobertura das audiências públicas, consideradas um dos mecanismos para assegurar a participação da sociedade civil nos debates políticos e administrativos. Entretanto, percebe-se que a ênfase dos veículos de comunicação da Câmara é a emissão de informações sobre as audiências, o que funciona, na prática, mais como um sistema de prestação de contas aos parlamentares e às comissões que requerem e promovem os debates com os representantes da sociedade civil. Isso contraria a própria natureza das audiências. Ademais, um sistema de informação voltado para a promoção da democracia não se sustenta apenas com a emissão de informação para o cidadão, mas necessariamente com atividades que tenham por objetivo implementar a

\section{As audiências públicas são um instrumento de participação subaproveitado pelo Parlamento e com pouca divulgação}

participação democrática dos receptores e usuários dos serviços de informação oferecidos, os quais, imperativamente, precisam reconhecer a legitimidade de tais serviços, o que pressupõe interatividade efetiva e não apenas interação episódica e assistemática.

Para que isso ocorra, é imprescindível que a instituição desenvolva mecanismos eficazes para aferir o interesse e a participação dos usuários nas audiências públicas, além da mera divulgação. Sem isso, o que se conclui é que o sistema de informação da Câmara dos Deputados, no caso em estudo, constitui uma ferramenta de divulgação institucional de informações legislativas, nos moldes tradicionais (um para muitos ou fluxo de informação em um só nível), mas não um sistema de informação política de caráter público, no sentido estrito do termo. Reiteramos que a informação política não deve ser confundida com a mera divulgação de dados sobre política, da mesma forma que a informação pública não se reduz às atividades institucionais protagonizadas por instituições governamentais ou do Estado.

Em suma, o que se deduz é que o pressuposto de que a informação política no Legislativo é um dos principais elementos para a aperfeiçoar a relação entre os representantes e seus eleitores não corresponde à prática, no caso da cobertura das audiências públicas. Esses entraves são maléficos à democracia, à cidadania, à representação política, à participação social e às próprias políticas públicas que são discutidas e analisadas durante as oitivas sociais. Tal diagnóstico demonstra a necessidade premente de revisão do sistema.

Uma revisão criteriosa, à luz de pressupostos editoriais discutidos com os próprios gestores e servidores responsáveis pelo funcionamento dos veículos poderia, de modo efetivo, contribuir para a concretização do ideal de tornar a informação política no Legislativo um dos principais elementos para aperfeiçoar a representação política, fortalecer a democracia e as práticas de cidadania 
e participação social. É oportuno salientar que isso também contribuiria para fortalecer o mecanismo das audiências públicas.

Apesar do avanço que representa a cobertura dessas audiências realizadas pela Câmara dos Deputados em termos de publicidade das questões relevantes para a sociedade, ainda há vários obstáculos à efetiva participação social no processo legislativo. O exemplo deles é o alcance limitado dos veículos legislativos. Apenas a TV Câmara e a Agência Câmara têm, realmente, alcance nacional. Mesmo assim, estão restritas à TV por assinatura e à internet, respectivamente. Desse modo, não se pode dizer que estejam disponíveis ao conjunto da população. Rádio e Jornal são ainda mais limitados, com alcance restrito ao Distrito Federal e alguns poucos cidadãos do resto do país ${ }^{10}$. Isso significa que grande parte da população brasileira continua sem acesso aos debates realizados no Parlamento por aqueles que, efetivamente, representam ou deveriam representar seus interesses - parlamentares e integrantes das entidades da sociedade civil.

A própria forma de organização das audiências, por outro lado, reflete o despreparo do Parlamento para conduzir discussões públicas que possam efetivamente refletir a diversidade de correntes de opinião existentes na sociedade. Além dos limites da própria instituição legislativa, é oportuno destacar a falta de habilidade dos parlamentares para uma discussão democrática e polêmica que ultrapasse as divisões entre governo e oposição, ou entre favoráveis e contrários a uma decisão. Da mesma forma, existem restrições do ponto de vista das instituições sociais e dos cidadãos que são convidados a participar dessas audiências públicas. Muitas vezes os agentes sociais utilizam o espaço para divulgação promocional das entidades que representam, sem contar os eventuais casos de autopromoção e de marketing pessoal. Além disso, a utilização da audiência apenas como vitrine para aumentar a visibilidade de demandas específicas demonstra seu uso como instrumento para conquistar a adesão de opiniões com fins estratégicos, tal qual ocorre nas campanhas eleitorais, mas não como ferramenta de ação comunicativa, no sentido habermasiano.

Em suma, trata-se de um instrumento de participação social subaproveitado pelo Parlamento brasileiro e com pouca divulgação no cenário nacional, o que nos leva a crer que seria necessária uma revisão geral das práticas adotadas atualmente. Da mesma forma, caberia às instituições sociais e aos próprios cidadãos reconsiderarem suas condutas, posturas e discursos quando participam dessas audiências, a fim de utilizá-las como oportunidade para o debate e não apenas como instrumento para o reforço de posições estratégicas ou ideológicas. Somente assim poderá ser construída uma real visibilidade das audiências como instrumento de cidadania e participação política, e não como meras etapas do processo legislativo formal para produção das políticas públicas no País.

\footnotetext{
${ }^{10}$ A Rádio Câmara é transmitida em Frequência Modulada (FM) no Distrito Federal, mas seu conteúdo pode ser aproveitado gratuitamente por qualquer emissora do país cadastrada no site. O jornal, por sua vez, tem uma edição semanal distribuída para os legislativos estaduais e municipais, além de órgãos dos demais poderes nos estados e municípios. Mesmo assim, nenhum dos dois veículos pode ser considerado de alcance nacional.
} 


\section{Referências bibliográficas}

ALDÉ, Alessandra. A construção da política: democracia, cidadania e meios de comunicação de massa. Rio de Janeiro: Editora FGV, 2004.

AVRITZER, Leonardo. Sociedade Civil, instituições participativas e representação: da autorização à legitimidade da ação. Rio de Janeiro, 2007, Vol. 50, no. 3 .

BARROS, A. T ; BERNARDES, C. B. ; LEMOS, C. R. F. As mídias legislativas e a redefinição da noticiabilidade política no Brasil. Em Questão (UFRGS. Impresso), v. 14, p. 11-23, 2008.

BASTOS, Celso Ribeiro e MARTINS, Ives Gandra da Silva. Comentários à Constituição do Brasil, São Paulo: Saraiva, 1995, Vol. 4, tomo I.

BRASIL. Site oficial da Câmara dos Deputados. www.camara.gov.br. Acesso em 12 jun. 2010.

DAL BOSCO, Maria Goretti. Audiência pública como direito de participação. Disponível em:

http://www.unigran.br/revistas/juridica/ed_anteriores/08/artigos/10.pdf. Acesso em: 12 jun. 2010

GUERRA, Alessandra Müller Vidal. A Participação Social e as Audiências Públicas. Texto apresentado ao Curso de Especialização em Legislativo e Políticas Públicas do Programa de Pós-Graduação do Centro de Formação, Treinamento e Aperfeiçoamento da Câmara dos Deputados (Cefor). Brasília, 2010.

HABERMAS. J. Teoria de la acción comunicativa I: Racionalidad de la acción y racionalización social. Madri: Taurus, 1987a.

. Teoria de la acción comunicativa II: Crítica de La Razón funcionalista. Madri: Taurus, 1987b.

MARQUES, Francisco Paulo J. A. Participação, instituições políticas e internet: um exame dos canais participativos nos portais da Câmara dos Deputados e da Presidência do Brasil. Revista Brasileira de Ciências da Comunicação, São Paulo, v.33, n.1, jan./jun.2010, p.53-80.

MATOS, Heloiza. Comunicação pública, democracia e cidadania: o caso do Legislativo. Trabalho apresentado no XXI Congresso Brasileiro de Ciências da Comunicação da Sociedade Brasileira de Estudos Interdisciplinares da Comunicação (Intercom). Rio de Janeiro, 1999. disponível em: http://www. fafich.ufmg.br/ larp/intercom99/matos.htm. Acesso em: 28 jun 2006. RENAULT, Letícia. Comunicação e política nos canais de televisão do Poder Legislativo no Brasil. Belo Horizonte: Assembléia Legislativa do Estado de Minas Gerais, 2004.

VALLA, Victor Vincent. Sobre participação popular: uma questão de perspectiva. Cadernos de Saúde Pública, Rio de Janeiro, 2010. Disponível em: http:// www.scielosp.org/scielo.php? pid =S0102-11X1998000600002\&script $=$ sci_ arttext\&tlng=pt Acesso em: 23 jun. 10. 